\title{
Bioadsorption of lead(II) over the pulp of Acrocomia aculeata
}

Alexandra Novak $^{1+}{ }^{\oplus}$, Fátima Yubero ${ }^{1}{ }^{\oplus}$, Diana Diez-Pérez-Núñez ${ }^{1} \oplus$, Fernando Luis Fertonani ${ }^{2} \oplus$, Brenda Gisselle Da Silva Britez ${ }^{1} \oplus$, Yenny Gonzalez ${ }^{1} \oplus$

1. National University of Asunción, Faculty of Chemical Sciences, San Lorenzo, Paraguay.

2. São Paulo State University, Institute of Biosciences, Languages and Exact Sciences, São José do Rio Preto, Brazil.

+Corresponding author: Alexandra Novak, Phone: +1 585-281-0077, Email address: at.novak23@gmail.com

\section{ARTICLE INFO}

Article history:

Received: July 21, 2020

Accepted: August 19, 2021

Published: October 01, 2021

Section Editor: Assis Vicente Benedetti

\section{Keywords}

1. adsorption

2. biomaterials

3. lead

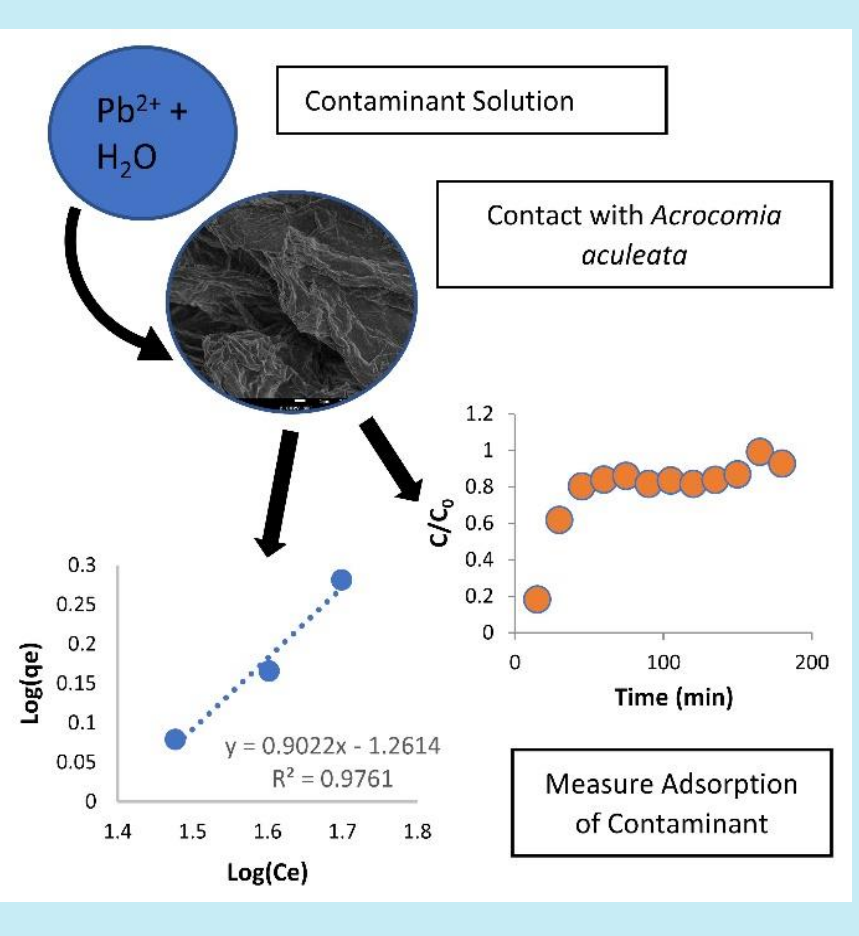

ABSTRACT: The adsorption of lead in aqueous solution onto Acrocomia aculeata pulp was examined. The pulp was characterized in the presence and absence of lead using Fourier transform infrared spectroscopy (FTIR), thermogravimetric analysis (TG-DTA), and scanning electron microscopy (SEM). Sulfur and oxygen bonds were responsible for adsorbing lead onto the pulp surface. The TG-DTA profile proved that adding sodium azide increases the pulp's thermal stability until $200{ }^{\circ} \mathrm{C}$. Adsorption data in batch and column systems were analyzed to understand the pulp adsorption compared to other biomaterials. In the batch experiments, the removal efficiency reached a maximum of $91.9 \%$ when a solution of 50 ppm of lead was placed in contact with the pulp for $30 \mathrm{~min}$ and fit Freundlich isotherm behavior. In the column experiments, the theoretical maximum adsorption capacity was found to be $11.97 \mathrm{mg} \mathrm{g}^{-1}$; more column data is needed to compare column results to other studies. Further studies to improve the pulp adsorption capacity are needed for it to be a competitive biomaterial for water treatment. 


\section{Introduction}

Lead is one of the five most harmful elements to human health (Tchounwou et al., 2012). Due to its high bioavailability, lack of biological function, and persistence in the environment, it is extremely toxic to ecosystems and living organisms (Jaishankar et al., 2014; Tchounwou et al., 2012). Some toxic effects of lead include damage to the central and peripheral nervous system, birth defects, inhibition of plant growth, and ecosystem bioaccumulation (Cardwell et al., 2013; Flora et al., 2012; Goyer, 1993; Jaishankar et al., 2014).

Though lead is naturally occurring, the majority of lead contamination results from anthropogenic sources (Tchounwou et al., 2012). Industrial sources of lead include fossil fuels, production of metals, mining, soldering, battery production, and pipping. Domestic sources of lead include decorative paint, children's toys, and cosmetics (Flora et al., 2012; Jaishankar et al., 2014; Tchounwou et al., 2012). Humans are exposed to lead from these products via respiration of dust containing lead or the ingestion of contaminated water. Cases of lead contamination are found on every continent, excluding Antarctica, and 49\% of children and $52 \%$ of adults in the world have blood levels of lead higher than 5 ug dL ${ }^{-1}$ (Kessler, 2014). Thus, it can be concluded that lead contamination is a global public health crisis (Tong et al., 2000).

The World Health Organization standard for lead in potable water is below $0.01 \mathrm{ppm}$, recommending that contaminated water be treated so that lead levels are below the standard (WHO, 2006). The most common methods of water treatment for lead are chemical precipitation and ionic exchange. Chemical precipitation uses hydroxides and sulfides to produce a solid precipitate containing lead. This process is fast and easy to control, however, the chemicals used and the disposal of toxic solids generate high operation costs. Ionic exchange uses a synthetic organic resin to attract soluble ions from a liquid phase to a solid phase. Although this method has low operation costs, it is very sensitive to $\mathrm{pH}$ changes and only works with low concentrations of lead (Gunatilake, 2015).

Bioadsorption is an alternative method for treating water contaminated with heavy metals such as lead. In this study, bioadsorption is defined as the mass transfer of a substance to the surface of a biomass-derived solid via physical and chemical interactions. Bioadsorption is efficient in purification and separation, low cost, and easy to control. Furthermore, it is a process that is environmentally friendly. Common materials for bioadsorption include agricultural wastes, biopolymers, and industrial byproducts (Gunatilake, 2015).

In Paraguay, a biomaterial of interest is the coconut palm Acrocomia aculeata, known by its common name as "mbokayá" (Yubero et al., 2015). Acrocomia aculeata is a species native to South America with a high cultivation potential in Paraguay, home to over $4,546,000$ hectares of the species (Plath et al., 2016). Unlike the African palm and soy, A. aculeata can be grown in a mixed culture and in infertile, sandy soils (Poetsch et al., 2012; Roman, 1996). This means that its cultivation does not compete with the nutrient-rich rainforest soil nor causes the loss of biodiversity associated with land clearing for monocultures (Plath $e t$ al., 2016). As this palm survives in extremely low temperatures, fire, and drought, it is resistant to extreme weather events brought on by climate change (Poetsch et al., 2012). The kernel oil from the coconut is already used in a variety of local products and industries in Paraguay, such as food, biofuel, cosmetics, and medicinal soap, and thus is an important economic resource for the country (Poetsch et al., 2012; Roman, 1996).

In addition to the environmental, social, and economic benefits of $A$. aculeata, the pulp of the coconut, a byproduct of kernel oil extraction, has proven capabilities in the bioadsorption of heavy metals from water. According to Yubero et. al (2015), the pulp of A. aculeata can adsorb up to $66 \%$ of chromium (VI), another heavy metal toxic to human health. Thus, it is probable that this material could effectively remove other heavy metals such as lead. This study aims to explore A. aculeata as a sustainable material for lead bioadsorption through the characterization of the pulp composition and structure and the analysis of lead adsorption in both column and batch systems.

\section{Experimental}

\subsection{Pulp preparation}

The coconuts were collected in February of 2016, in semi-open field at the Jack Norment Camp in Caacupé, Paraguay. The pulp was processed by the Botany and Physical Chemistry Departments at Universidad Nacional de Asunción. First, the epicarp was removed and mesocarp cuts were made. The slightly insoluble fibers were then dried at $40{ }^{\circ} \mathrm{C}$ for two days (González et al., 2018; Yubero et al., 2016a; b). The size of the dry fiber was sieved for size selection, to be between 297 and $350 \mu \mathrm{m}$. To conserve the fiber, $0.5 \mathrm{~g}$ of 
sodium azide was added and homogenized in about $4 \mathrm{~g}$ of the size-selected fiber.

\subsection{Characterization methods}

Fourier transform infrared spectroscopy (FTIR) analysis from $500-4000 \mathrm{~cm}^{-1}$ was conducted on the native pulp and the pulp in contact with a $25 \mathrm{ppm}$ $\mathrm{Pb}$ (II) solution for $5 \mathrm{~min}, 30 \mathrm{~min}$, and $5 \mathrm{~h}$, using the Shimadzu Europa GmbH IR Prestige-21. Thermogravimetric analysis (TG-DTA) was carried out using TA Instruments ST 2960 Simultaneous DTADTG on a sample of $\mathrm{m}=5.6 \mathrm{mg}$ of native pulp/sodium azide mix. The sample was heated at $\beta=20{ }^{\circ} \mathrm{C} \mathrm{min}^{-1}$

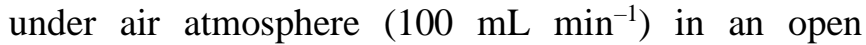
aluminum crucible $(70 \mu \mathrm{L})$ during thermogravimetric analysis (TG-DAT analysis. Scanning electron microscopy (SEM) images of the pulp azide mix after contact with $\mathrm{Pb}$ (II) were taken using FEG-SEM JEOL Model 7500F.

\subsection{Solution preparation}

The distilled water was tested with a PHS-38W microprocessor from Bante Instruments. The $\mathrm{pH}$ was found to have a $\mathrm{pH}$ of 5.84 at $25.4{ }^{\circ} \mathrm{C}$. As lead has a solubility between a $\mathrm{pH}$ of 2 to 7 , distilled water was used in the following solutions (Wang et al., 2017). Lead nitrate, $\mathrm{Pb}\left(\mathrm{NO}_{3}\right)_{2}$, were used in the preparation of all solutions.

A $1 \mathrm{~L}$ solution of $50 \mathrm{ppm} \mathrm{Pb}\left(\mathrm{NO}_{3}\right)_{2}$ was prepared using $50 \mathrm{mg}$ of anhydrous $\mathrm{Pb}\left(\mathrm{NO}_{3}\right)_{2}$. Solutions of 30 , 40 , and $50 \mathrm{ppm} \mathrm{Pb}\left(\mathrm{NO}_{3}\right)_{2}$ were prepared by adding 30 , 40 , and $50 \mathrm{~mL}$ of the $50 \mathrm{ppm} \mathrm{Pb}\left(\mathrm{NO}_{3}\right)_{2}$ solution to $50 \mathrm{~mL}$ volumetric flasks and filling them with distilled water.

\subsection{Batch study}

To prepare the pulp for batch experiments, $200 \mathrm{mg}$ samples of the pulp were washed three times with $25 \mathrm{~mL}$ of distilled water. The batch experiment was carried out by adding a sample of $200 \mathrm{mg}$ of pulp to a $13 \mathrm{~mL}$ solution with an initial concentration of either 30 , 40 , or $50 \mathrm{ppm} \mathrm{Pb}$ (II) to conical centrifuge tubes. Each sample was rotated for a required time of either $5 \mathrm{~min}, 30 \mathrm{~min}$, and $5 \mathrm{~h}$ at $8 \mathrm{rpm}$. Next, the pulp and solution were centrifuged for $5 \mathrm{~min}$ at $6000 \mathrm{rpm}$. The supernatant was extracted and the final concentration of $\mathrm{Pb}$ (II) was tested using AA-6300 Shimadzu atomic absorption spectrometer. It must be noted that this experiment was performed in duplicate (i.e. two samples of pulp in contact with $30 \mathrm{ppm} \mathrm{Pb}(\mathrm{II})$ for 5 min, two samples in contact with $30 \mathrm{ppm} \mathrm{Pb}$ (II) for $30 \mathrm{~min})$.

The Langmuir (Eq. 1) and Freundlich (Eq. 2) adsorption isotherms were applied to the batch data using the following equations.

$\frac{1}{q_{e}}=\frac{1}{K_{L} q_{m}} \frac{1}{c_{i}}+\frac{1}{Q_{m}}$

$\log q_{e}=\log K_{F}+\frac{1}{n} \log c_{i}$

where $K_{L}$ is the Langmuir constant $\left(\mathrm{L} \mathrm{mg}^{-1}\right), q_{m}$ is the maximum adsorbed capacity (when the adsorbate monolayer has formed, $\left.\mathrm{mg} \mathrm{g}^{-1}\right), K_{F}$ is the Freundlich constant for adsorption capacity $\left(\mathrm{L} \mathrm{mg}^{-1}\right), n$ is Freundlich constant for adsorption intensity, and $c_{i}$ is the initial concentration adsorbate in solution $\left(\mathrm{mg} \mathrm{L}^{-1}\right)$. $q_{e}$ is the adsorption capacity at equilibrium $\left(\mathrm{mg} \mathrm{g}^{-1}\right)$, solved for using Eq. 3.

$q_{e}=\frac{c_{i}-c_{f}}{m} \times V$

where $c_{f}$ is the final solution $\left(\mathrm{mg} \mathrm{L}^{-1}\right), m$ is the mass of adsorbent $(\mathrm{g})$, and $V$ is the volume of solution $(\mathrm{L})$.

Removal efficiency (Eq. 4) was also calculated for batch data using the following equation.

RemovalEfficiency $=\frac{c_{i}-c_{f}}{c_{i}} \times 100$

\subsection{Column study}

A $5 \mathrm{~mL}$ syringe with needle was used as the column. A sheet of packing plastic was placed at the bottom of the syringe and $200 \mathrm{mg}$ of pulp were loaded into the column. The syringe needle was connected to a tube that fed through a peristaltic pump that regulated a flow rate of $4 \mathrm{~mL} \mathrm{~min}^{-1}$, as seen in Fig. 1 .

Twenty-five $\mathrm{mL}$ of distilled water were passed through the column to stabilize the column bed. After the pulp was stabilized, a $35 \mathrm{ppm} \mathrm{Pb}$ (II) solution was continuously passed through the column. Over a 3-time period, $15 \mathrm{~mL}$ samples of effluent solution were collected every $15 \mathrm{~min}$ in conical centrifuge tubes. In between sampling times, the effluent was collected in a waste beaker. The levels of $\mathrm{Pb}$ (II) in the conical centrifuge tube samples were tested using atomic absorption spectroscopy. 


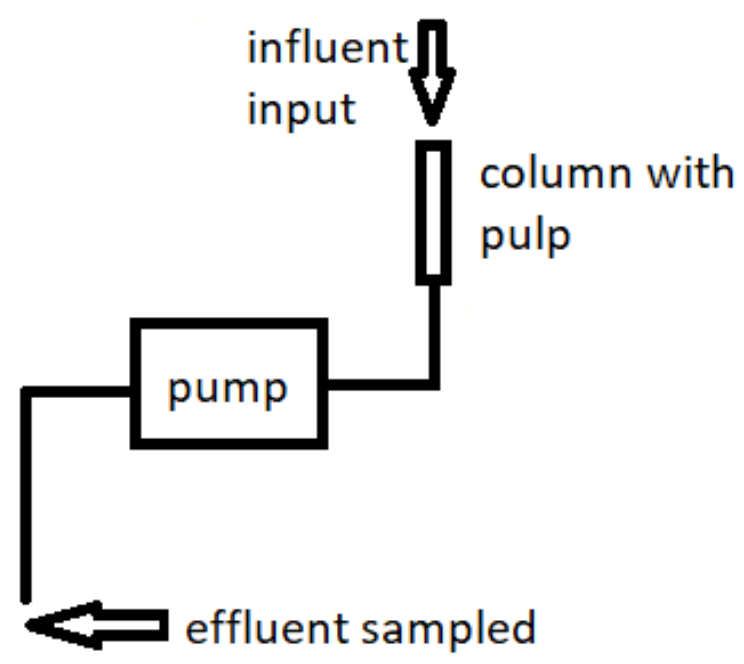

Figure 1. Column experiment configuration.

The Thomas (Eq. 5) and Yoon-Nelson (Eq. 6) models were applied to column data using the following equations.

$\ln \left[\left(\frac{C_{o}}{C_{t}}\right)-1\right]=\frac{K_{T H} q_{T H} m}{Q}+K_{T H} C_{o} t$

where $C_{o}$ is the original concentration of the solution ( $\left.\mathrm{mg} \mathrm{L}^{-1}\right), C_{t}$ is the concentration of the effluent solution $\left(\mathrm{mg} \mathrm{L}^{-1}\right), Q$ is the flow rate $\left(\mathrm{mL} \mathrm{min}^{-1}\right), K_{T H}$ is the Thomas model constant $\left(\mathrm{mL} \mathrm{mg}{ }^{-1} \mathrm{~min}^{-1}\right), q_{T H}$ is the theoretical adsorption capacity, and $\mathrm{t}$ is the time (min).

$\ln \left(\frac{C_{t}}{C_{o}-C_{t}}\right)=t K_{Y N}-\tau K_{Y N}$

where $C_{o}$ is the original concentration of the solution ( $\left.\mathrm{mg} \mathrm{L}^{-1}\right), C_{t}$ is the concentration of the effluent solution $\left(\mathrm{mg} \mathrm{L}^{-1}\right)$, flow rate of the influent solution $\left(\mathrm{mL} \mathrm{min}^{-1}\right)$, $t$ is the time ( $\mathrm{min}), K_{Y N}$ is the Yoon-Nelson constant $\left(\mathrm{min}^{-1}\right)$, and $\tau$ is the time to reach $50 \%$ saturation of the column.

\section{Results and discussion}

\subsection{Materials characterization}

The data for the infrared (IR) spectrum of the native pulp is found in Tab. 1. The native pulp had a characteristic fingerprint region, defined by bands 1-8 in Tab. 1, with representative bands at 1735,1374 , and $1064 \mathrm{~cm}^{-1}$ (Yubero et al., 2015). These bands correspond with $\mathrm{C}=\mathrm{N} / \mathrm{C}=\mathrm{O}, \mathrm{C}-\mathrm{O}-\mathrm{C}$, and $\mathrm{C}=\mathrm{S} / \mathrm{S}=\mathrm{O}$ bonds (Chang, 1981).
Table 1. Fourier transform infrared (FTIR) spectrum bands of A. aculeata pulp.

\begin{tabular}{|c|c|c|c|}
\hline $\mathbf{1}$ & Band $/ \mathbf{c m}^{-\mathbf{1}}$ & Intensity & Area/a.u. $\mathbf{c m}^{-\mathbf{1}}$ \\
\hline $\mathbf{2}$ & 996 & 1.260 & 27.17 \\
\hline $\mathbf{3}$ & 1034 & 1.404 & 64.96 \\
\hline $\mathbf{4}$ & 1068 & 1.426 & 4.12 \\
\hline $\mathbf{5}$ & 1160 & 1.272 & 46.69 \\
\hline $\mathbf{6}$ & 1249 & 1.331 & 72.19 \\
\hline $\mathbf{7}$ & 1330 & 1.219 & 9.39 \\
\hline $\mathbf{8}$ & 1378 & 1.291 & 12.37 \\
\hline $\mathbf{9}$ & 2348 & 1.366 & 7.72 \\
\hline $\mathbf{1 0}$ & 2374 & 1.209 & 10.41 \\
\hline $\mathbf{1 1}$ & 2866 & 1.204 & 19.64 \\
\hline $\mathbf{1 2}$ & 2922 & 1.281 & 8.64 \\
\hline $\mathbf{1 3}$ & 3005 & 1.320 & 20.30 \\
\hline & & 1.271 & 8.58 \\
\hline
\end{tabular}

When the pulp was in contact with a $25 \mathrm{ppm} \mathrm{Pb}$ (II) solution, the bands in the fingerprint region shrink in intensity as the contact time with the lead solution increased, as seen in Fig. 2. This change in intensity, an indicator of change in dipole movement, indicates that the oxygen and sulfur bonds are most likely involved in capturing the $\mathrm{Pb}$ (II). Additionally, a band appears at around $2300 \mathrm{~cm}^{-1}$ in the $\mathrm{Pb}(\mathrm{II})$ contact spectra, highlighted in Fig. 2, at a stronger intensity than in the raw pulp IR spectrum. This band could indicate the presence of $\mathrm{Pb}(\mathrm{II})$ nitrate.

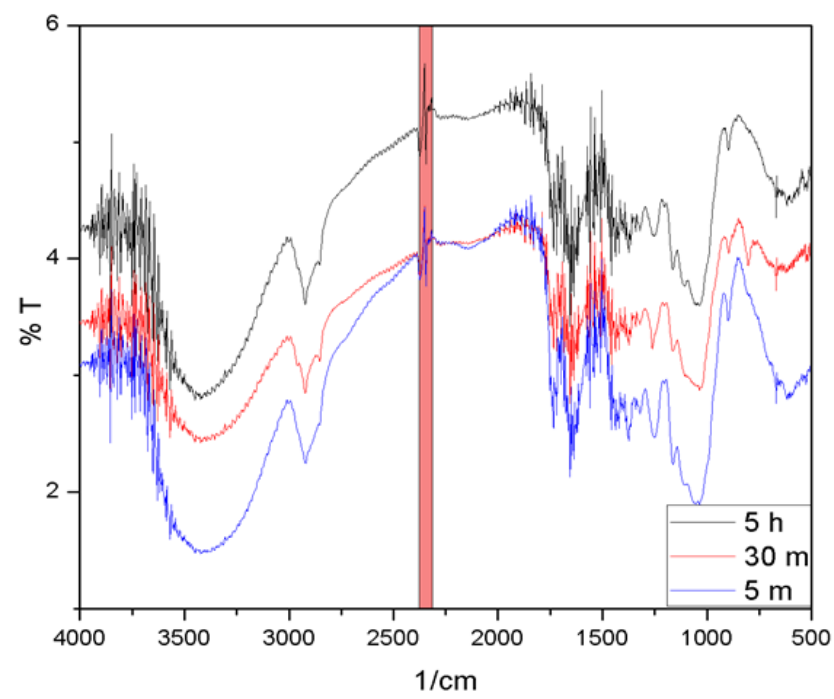

Figure 2. Fourier transform infrared spectrum (FTIR) of A. aculeata pulp in contact with $25 \mathrm{ppm} \mathrm{Pb}$ (II) solution for $5 \mathrm{~min}, 30 \mathrm{~min}$, and $5 \mathrm{~h}$; insert: expanded region of $2340-2380 \mathrm{~cm}^{-1}$.

The results of the scanning electron microscopy (SEM) imaging are found in Fig. 3. These images reveal the pulp to have a rough, fibrous surface texture. 
The thermogravimetric analysis (TGA) profile of the pulp azide mixture (Fig. 4) was compared to the TGA of A. aculeata pulp in absence of sodium azide, from Fig. 4. It must be noted that in Corrêa et al. (2019) the pulp was heated at $10{ }^{\circ} \mathrm{C} \mathrm{min}{ }^{-1}$ under synthetic air while the conditions for this experiment was $20{ }^{\circ} \mathrm{C}$ $\mathrm{min}^{-1}$. The raw pulp had four decomposition steps, while the thermogravimetric/derivative thermogravimetric (TG/DTG) curves of the pulp sodium azide mixture reveals that there are three distinct decomposition steps (Fig. 4). In the raw pulp TG/DTG curve, the first step occurred between room temperature and $160{ }^{\circ} \mathrm{C}$ and was endothermic due to the presence of water in the fibers (Corrêa et al., 2019). Similarly, the first step in the pulp azide mechanical mixture is endothermic between 25 and $100{ }^{\circ} \mathrm{C}$ and can be associated with water molecule evolution.
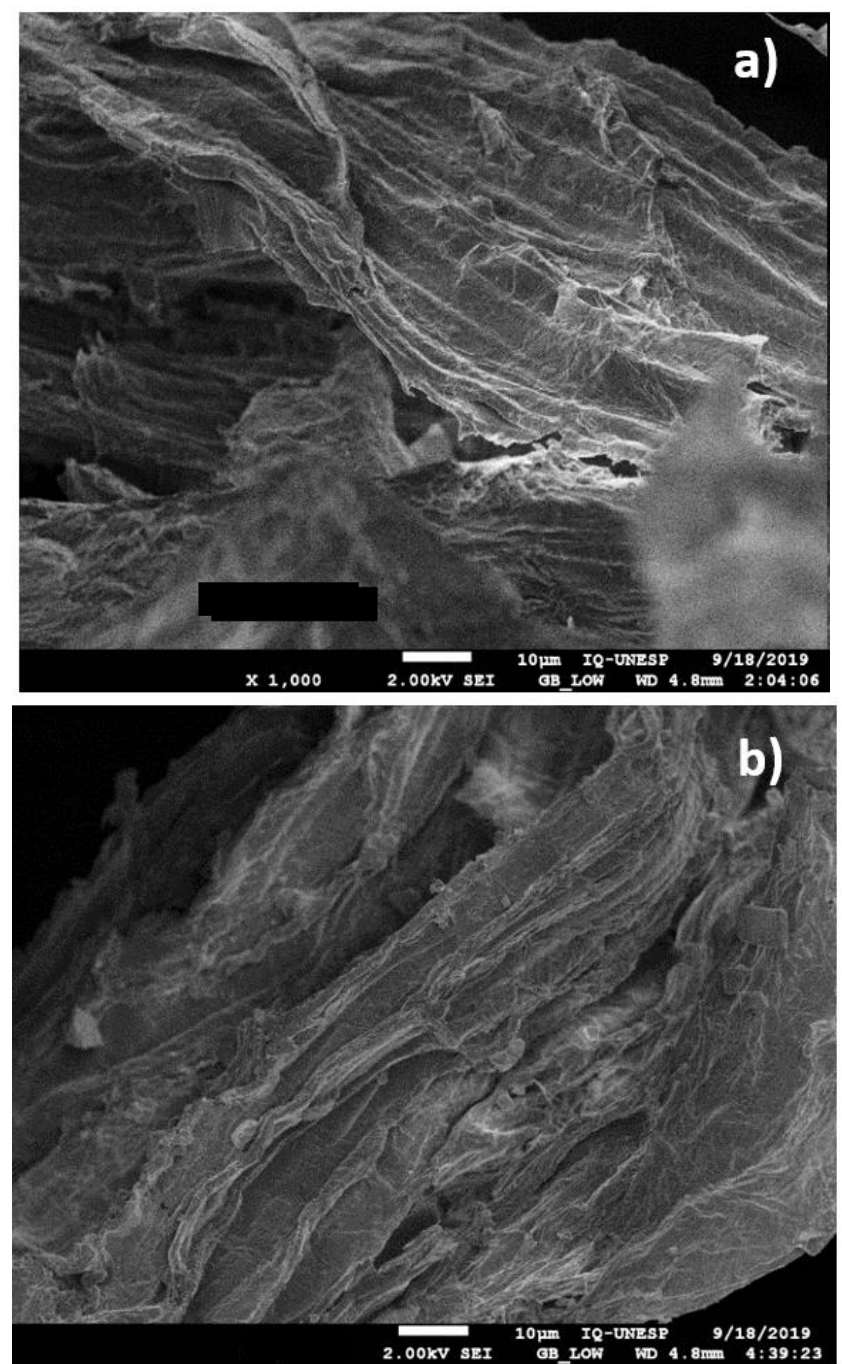

Figure 3. Field emission gun scanning electron microscope (FEG-SEM) mixed (secondary electron and backscatter electron) image of $A$. aculeata pulp with $\mathrm{Pb}(\mathrm{II})$ in (a) batch and (b) column.
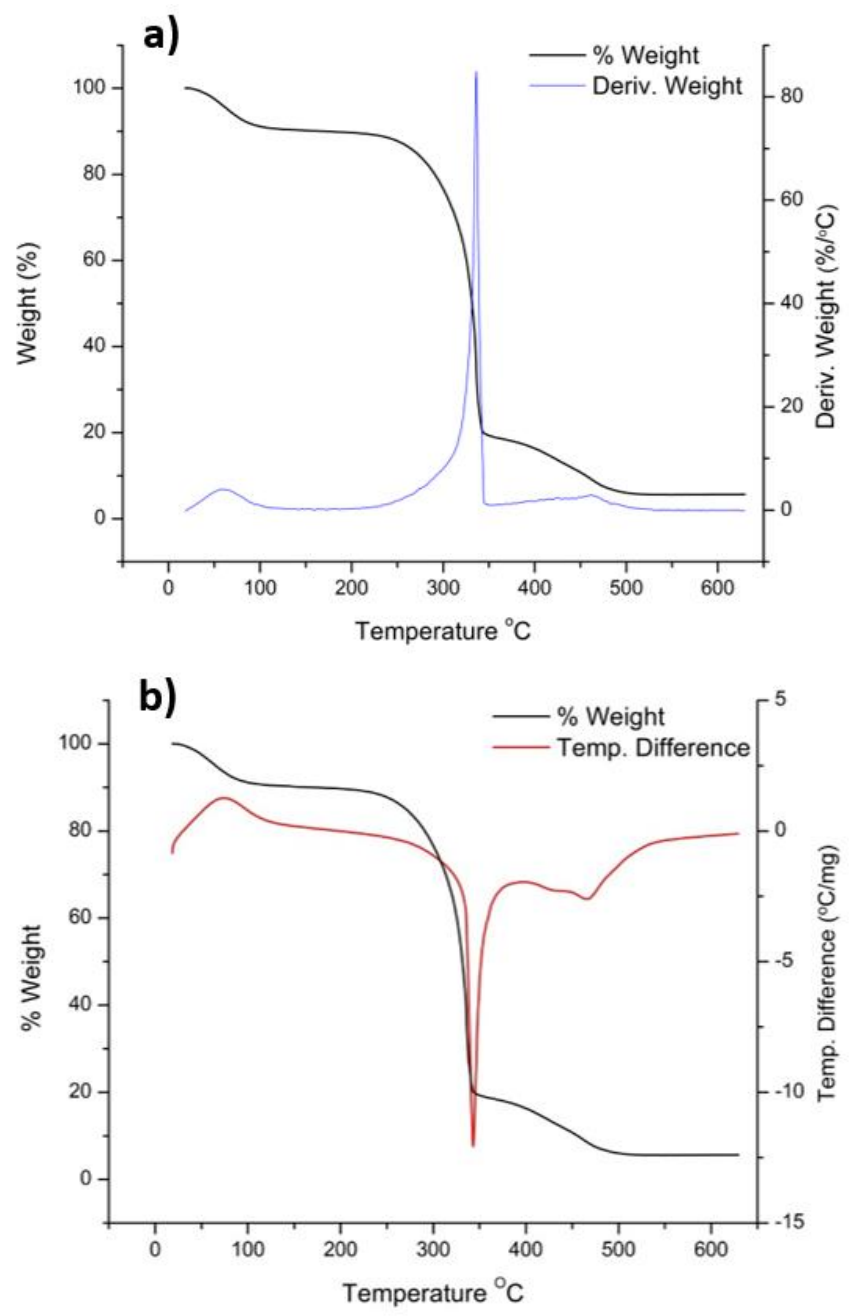

Figure 4. Thermogravemetric analysis (TGA) profile of A. aculeata pulp, \% weight with (a) TG and DTG and (b) TG-DTA; mass sample of $5.6 \mathrm{mg} ; \beta=20^{\circ} \mathrm{C}$ $\mathrm{min}^{-1}$; air $\left(100 \mathrm{~mL} \mathrm{~min}^{-1}\right)$; open aluminum crucible $(70 \mathrm{~L})$.

The next decomposition step in the raw pulp TGA was exothermic and the largest; it occurred between approximately 190 and $300{ }^{\circ} \mathrm{C}$ and can be attributed to the decomposition of hemicellulose and cellulose. This step was followed by two small exothermic mass losses between approximately 390 and $425{ }^{\circ} \mathrm{C}$ that can be attributed to the decomposition of lignin (Corrêa et al., 2019). On the other hand, the pulp azide mixture demonstrated thermal stability until about $200{ }^{\circ} \mathrm{C}$, proving that the sodium azide causes a slight stabilization in the material. The following step for the sodium azide mixture is strongly exothermic and can be associated with the kinetically fast decomposition of 
cellulose and the formation of the metallic $\mathrm{Na}$ species from sodium azide, which both simultaneously occur between 200 and $340{ }^{\circ} \mathrm{C}$. The largest percentage weight loss occurs during this step at $\mathrm{T}^{\mathrm{DTA}}{ }_{\text {peak }}=336^{\circ} \mathrm{C}$, which is right around the temperature that sodium azide decomposes according to literature. It can be concluded that the presence of sodium azide accelerates the decomposition of the material in this step. The residues from the decomposition reaction of cellulose and sodium azide to metallic $\mathrm{Na}$ then decomposes in the step between 350 and $510{ }^{\circ} \mathrm{C}$. The DTG and DTA curves are in agreement with each other and the literature, revealing two small peaks that are associated with the slow kinetics steps of consecutive reactions (Fujimoto et al., 1990). A total of $94.3 \%$ of the pulp sodium azide mixture decomposed.

\subsection{Batch study}

In the batch study, the removal efficiency (see Eq. 4 ), or performance in terms of amount of lead removed was found to reach a maximum of $91.9 \%$ when a 13 $\mathrm{mL}$ solution of $50 \mathrm{ppm}$ of $\mathrm{Pb}(\mathrm{II})$ was placed in contact with $200 \mathrm{mg}$ of pulp for $30 \mathrm{~min}$. The Langmuir and Freundlich adsorption isotherms for $5 \mathrm{~min}$ of contact with the lead solution are found in Figs. 5 and 6, respectively. It is important to note that most results from the $5 \mathrm{~h}$ and 30 min contact time were found to be under the limit of quantification of the instrument $(6.30 \mathrm{ppm} \mathrm{Pb}(\mathrm{II}))$, so these isotherms were not included in this paper (Silva, 2016). The results from the application of the Langmuir and Freundlich isotherm models applied to the batch results are summarized in Tab. 2.

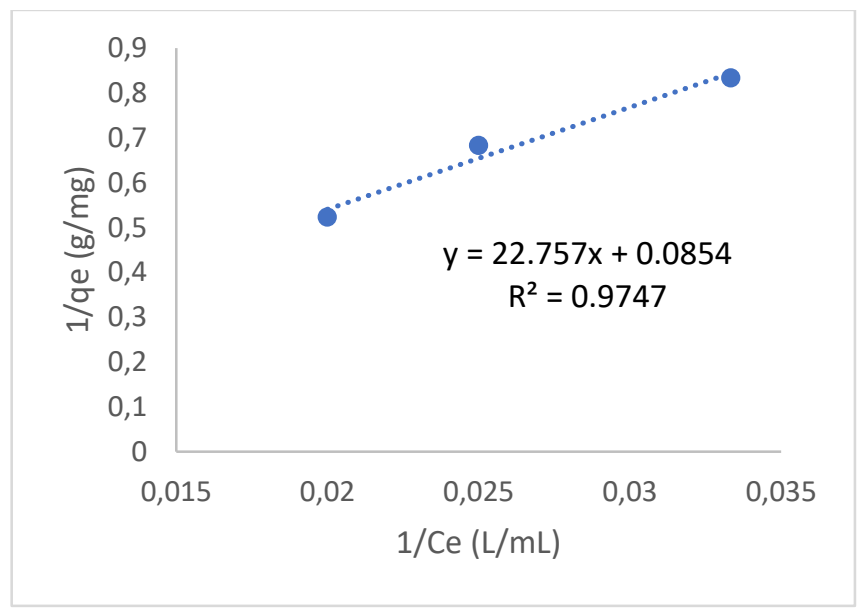

Figure 5. Langmuir isotherm of $\mathrm{Pb}(\mathrm{II})$ adsorption for 5 min contact time with $A$. aculeata.

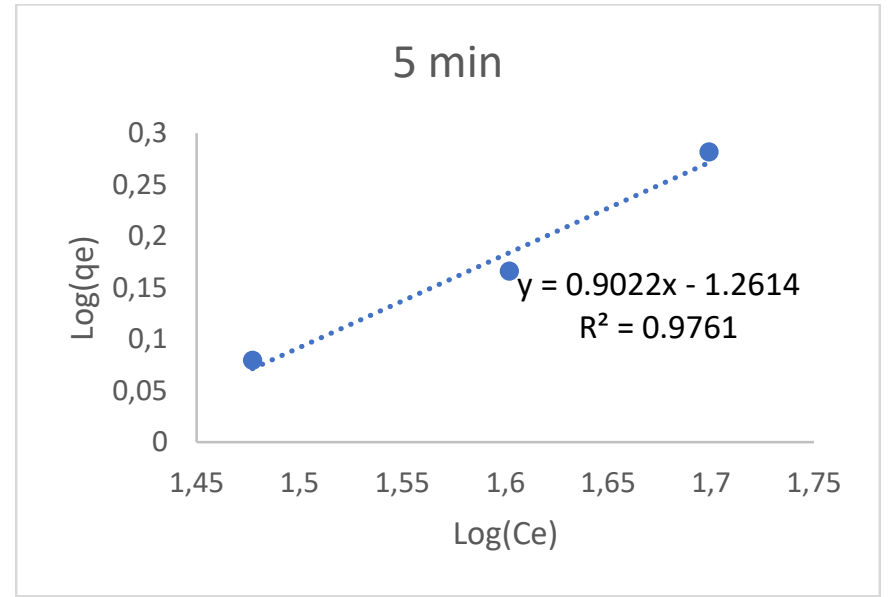

Figure 6. Freundlich isotherm of $\mathrm{Pb}(\mathrm{II})$ adsorption for 5 min contact time with $A$. aculeata.

Table 2. Langmuir and Freundlich isotherms of $\mathrm{Pb}(\mathrm{II})$ adsorption in batch for 5 min contact time.

\begin{tabular}{|c|c|c|c|c|c|}
\hline \multicolumn{2}{|c|}{ Langmuir isotherm } & \multicolumn{3}{c|}{ Freundlich isotherm } \\
\hline $\mathrm{q}_{\mathrm{m}}$ & $\mathrm{K}_{\mathrm{L}}$ & $\mathrm{R}^{2}$ & $\mathrm{~K}_{\mathrm{L}}$ & $\mathrm{n}$ & $\mathrm{R}^{2}$ \\
\hline 11.71 & 0.0037 & 0.9747 & 0.0548 & 1.108 & 0.9761 \\
\hline
\end{tabular}

The $\mathrm{R}^{2}$ value suggest that the Freundlich model fits the adsorption behavior slightly more than the Langmuir model. This indicates that the distribution of surface energy is heterogenous. The Freundlich model also is in accordance with the SEM images, as Freundlich adsorption commonly occurs on rough surfaces (Fig. 3) (Chang, 1981). The $n$ value, the Freundlich constant for adsorption intensity is greater than 1 , which indicates that the adsorption reaction is kinetically favorable. The Freundlich constant for adsorption capacity, $K_{F}$, however, is low compared to other biomaterials in batch, as seen in Tab. 3. The pulp was found to have a low adsorption capacity, $q_{e}$ (Eq. 3), of $2.3 \mathrm{mg} \mathrm{g}^{-1}$ in comparison to other biomaterials (Tab. 3 ). Since the adsorption capacity defines the amount of adsorbate taken up by the adsorbent, the low value indicates that it is not a promising biomaterial for filtration (Tab. 3). Future optimization studies regarding ideal conditions for adsorption or chemical treatment of the material are needed to improve the adsorption capacity. 
Table 3. Comparison of Freundlich adsorption parameters for various biomaterials.

\begin{tabular}{|l|c|c|c|c|c|}
\hline Material & Source & KF & n & $\mathbf{R}^{\mathbf{2}}$ & $\left.\mathbf{q e}^{(\mathbf{m g} \text { g- }}{ }^{\mathbf{1}}\right)$ \\
\hline Corn cobs & Stefan et al., 2010 & 0.40 & 1.5 & 0.8794 & N/A \\
\hline Hazelnut shell & Pehlivan et al., 2009 & 4.28 & 1.6 & 0.9360 & 28.18 \\
\hline Almond shell & Pehlivan et al., 2009 & 0.18 & 1.9 & 0.9260 & 8.08 \\
\hline Activated carbon & Singanan, 2011 & 1.25 & 3.5 & 0.9626 & N/A \\
\hline Rice husk & Zulkali et al., 2006 & 0.81 & 1.9 & 0.9851 & 5.69 \\
\hline Modified peanut husk & Li et al., 2007 & 0.34 & 0.5 & 0.9773 & 4.66 \\
\hline A. Aculeata pulp & This study & 0.05 & 1.1 & 0.9761 & 2.30 \\
\hline
\end{tabular}

\subsection{Column study}

The experimental breakthrough curve from the column experiment is found in Fig. 7 and the breakthrough parameters, along with the Thomas and Yoon-Nelson results, are summarized in Tab. 4. The breakthrough curve resembles the typical shape for column adsorption. The breakthrough time, which is defined as the time at which the concentration of the effluent solution is equal to $5 \%$ of the influent concentration, occurs in the first $15 \mathrm{~min}$. This signifies an efficient mass transfer rate. The exhaustion time, the time at which the concentration of the effluent solution reaches $95 \%$ of the influent concentration, was found to occur between 2.50 and $2.75 \mathrm{~h}$. The long exhaustion time indicates that the pulp-column system would have a long operating life.

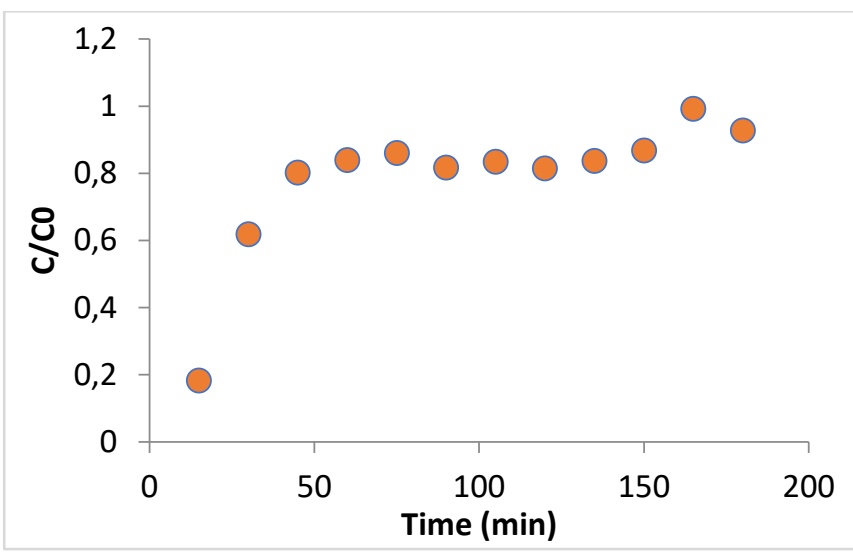

Figure 7. Experimental breakthrough curve for $\mathrm{Pb}(\mathrm{II})$ adsorbed on A. aculeata pulp.

Table 4. The parameters in fixed-bed experiments for adsorption of $\mathrm{Pb}(\mathrm{II})$ on A. aculeata.

\begin{tabular}{|c|c|c|c|c|c|c|c|c|}
\hline \multicolumn{3}{|c|}{ Thomas model } & \multicolumn{4}{c|}{ Yoon-Nelson model } \\
\hline $\boldsymbol{K}_{T H}\left(\mathrm{~mL} \mathrm{mg}^{-1} \mathrm{~min}^{-1}\right)$ & $q_{T H}\left(\mathrm{mg} \mathrm{g}^{-1}\right)$ & $\mathrm{R}^{2}$ & $K_{Y N}(1 / \mathrm{min})$ & $\mathrm{T}(\mathrm{min})$ & $\mathrm{R}^{2}$ & $\mathrm{t}_{\mathrm{b}}(\mathrm{min})$ & $\mathrm{t}_{\mathrm{e}}(\mathrm{min})$ & $\mathrm{R}_{\mathrm{q}}$ \\
\hline 0.5714 & 11.97 & 0.5782 & 0.020 & 17.15 & 0.5782 & $0-15$ & $150-165$ & 1.022 \\
\hline
\end{tabular}

The Thomas (Eq. 5) and Yoon-Nelson (Eq. 6) are mathematical models for Langmuir adsorption used to describe the performance of the column. The Thomas model is typically used to calculate $q_{t h}$, the theoretical adsorption capacity of the pulp, which describes the maximum solid phase concentration of $\mathrm{Pb}$ (II) on the pulp. This was found to be $11.97 \mathrm{mg} \mathrm{g}^{-1}$. The YoonNelson model is a model for fixed bed, single component adsorption that assumes the decrease in probability of adsorption for each $\mathrm{Pb}$ (II) molecule is proportionate to the probability of breakthrough on the pulp by the $\mathrm{Pb}$ (II). When applied to the data from the column study, the Thomas and Yoon-Nelson models had low $R^{2}$ and, therefore, did not fit the adsorption behavior of $\mathrm{Pb}$ (II) (Tab. 2). The $R_{q}$, which is the ratio of the theoretical adsorption maximum in column compared to batch, was calculated using the results from the Thomas model in column and Langmuir model. The ratio of 1.022 shows that the column and batch systems have almost equal efficiency in adsorption of $\mathrm{Pb}(\mathrm{II})$, however, as the adsorption does not follow Langmuir behavior and the Thomas and Yoon-Nelson models have poor $R^{2}$ coefficients, the column results cannot truly compare the efficacies of both systems. It is necessary that more column data be collected so that an accurate performance assessment can be made.

\section{Conclusions}

The IR characterization revealed that bonds containing oxygen and sulfur were involved in the adsorption of $\mathrm{Pb}(\mathrm{II})$ ions from water. The TGA analysis demonstrated that sodium azide increases the pulp stability. In accordance with the rough surface revealed from the SEM images, the pulp adsorption of $\mathrm{Pb}(\mathrm{II})$ specie follows the Freundlich model preferentially, indicating that the binding sites have a 
heterogenous distribution of energy and do not form a single layer. The adsorption parameters in batch, however, indicate lower performance when compared to other biomaterials. While the breakthrough curve from the column experiments demonstrated efficiency and operation durability, more column experiments need to be conducted in order to determine which model best describes the adsorption behavior and performance. Future studies on improving the adsorption capacity of $A$. aculeata are needed to understand this biomaterial full capabilities as a sustainable water treatment for $\mathrm{Pb}$ (II).

\section{Authors' contribution}

Conceptualization: Novak, A.; Yubero, F.

Data curation: Novak, A.

Formal Analysis: Novak, A.

Funding acquisition: Novak, A.

Investigation: Novak, A.; Yubero, F.; Diez-PérezNúñez, D.; Fertonani, F. L.; Da Silva Britez, B. G.; González, Y.

Methodology: Novak, A.; Yubero, F.; Diez-PérezNúñez, D.; Fertonani, F. L.

Project Administration: Novak, A.; Yubero, F.

Resources: Yubero, F.; Diez-Pérez-Núñez, D.; Fertonani, F. L.; González, Y.

Software: Not applicable

Supervision: Yubero, F.; Fertonani, F. L.

Validation: Yubero, F.; Diez-Pérez-Núñez, D.;

Fertonani, F. L.; González, Y.

Visualization: Novak, A.

Writing - original draft: Novak, A.

Writing - review \& editing: Novak, A.; Yubero, F.; Fertonani, F. L.

\section{Data availability statement}

All data in this report is licensed under creative commons.

\section{Funding}

Fulbright U.S. Student Study/Research Grant 2019, The Fulbright Program, https://us.fulbrightonline.org/countries/westernhemisphere/paraguay/110

\section{Acknowledgments}

We thank the Physical Chemistry Department for all the support, resources, and mentorship they provided as well as the Fulbright Program for funding this project. We also would like to thank Redox Química, the Medical Control Laboratory of the National University of Asunción, School of Chemical Sciences, and the Department of Chemistry and Environmental Sciences at São Paolo State University in São José do Rio Preto for providing us with the instruments and chemical characterization necessary for this study. Finally, we thank the Botany Department of the National University of Asunción, School of Chemical Sciences for collecting the coconuts used in the experiment.

\section{References}

Cardwell, R. D.; DeForest, D. K.; Brix, K. V.; Adams, W. J. $\mathrm{Do} \mathrm{Cd}, \mathrm{Cu}, \mathrm{Ni}, \mathrm{Pb}$, and $\mathrm{Zn}$ biomagnify in aquatic ecosystems. In Reviews of Environmental Contamination and Toxicology; Springer, 2013; pp 101-122. https://doi.org/10.1007/978-1-4614-6898-1_4

Chang, R. Physical chemistry with applications to biological systems; Collier Macmillan, 1981.

Corrêa, A. C.; Carmona, V. B.; Simão, J. A.; Galvani, F.; Marconcini, J. M.; Mattoso, L. H. C. Cellulose Nanocrystals from Fibers of Macauba (Acrocomia Aculeata) and Gravata (Bromelia Balansae) from Brazilian Pantanal. Polymers 2019, 11 (11), 1785. https://doi.org/10.3390/polym11111785

Flora, G.; Gupta, D.; Tiwari, A. Toxicity of lead: a review with recent updates. Interdiscip. Toxicol. 2012, 5 (2), 47-58. https://doi.org/10.2478/v10102-012-0009-2

Fujimoto, Y.; Ando, T.; Morisaki, S. Thermal stability of sodium azide. Azi ka natorium no netsu anteisei. Kogyo Kayaku 1990, 51 (3), 148-156.

González, Y.; García, M. G.; Arrúa, R. D.; López, M.; Bernal, C.; Ayala, J.; Yubero, F. Morfología, anatomía estructural y actividad lipasa de la pulpa de "coco", Acrocomia aculeata (Jacq) Lodd. ex Mart. (Arecaceae) en función al tiempo de colecta. Rojasiana 2018, 17 (1), 73-80.

Goyer, R. A. Lead toxicity: current concerns. Environ. Health Perspect. 1993, 100, 177-187. https://doi.org/10.1289/ehp.93100177

Gunatilake, S. K. Methods of removing heavy metals from industrial wastewater. J. Multidiscip. Eng. Sci. Stud. 2015, I (1), 12-18.

Jaishankar, M.; Tseten, T.; Anbalagan, N.; Mathew, B. B.; Beeregowda, K. N. Toxicity, mechanism and health effects of some heavy metals. Interdiscip. Toxicol. 2014, 7 (2), 6072. https://doi.org/10.2478/intox-2014-0009 
Kessler, R. Lead-based decorative paints: where are they still sold-and why? Environ. Health Perspect. 2014, 122 (4), A97-A103. https://doi.org/10.1289/ehp.122-A96

Li, Q.; Zhai, J.; Zhang, W.; Wang, M.; Zhou, J. Kinetic studies of adsorption of $\mathrm{Pb}$ (II), $\mathrm{Cr}$ (III) and $\mathrm{Cu}$ (II) from aqueous solution by sawdust and modified peanut husk. $J$. Hazard. Mater. 2007, $141 \quad$ (1), 163-167. https://doi.org/10.1016/j.jhazmat.2006.06.109

World Health Organization. Guías para la calidad del agua potable; WHO, 2006. https://www.who.int/water_sanitation_health/dwq/gdwq3_es _full1_lowsres.pdf (accessed 2021-31-08).

Pehlivan, E.; Altun, T.; Cetin, S.; Bhanger, M. I. Lead sorption by waste biomass of hazelnut and almond shell. $J$. Hazard. Mater. 2009, 167 (1-3), 1203-1208. https://doi.org/10.1016/j.jhazmat.2009.01.126

Plath, M.; Moser, C.; Bailis, R.; Brandt, P.; Hirsch, H.; Klein, A.-M.; Walmsley, D.; von Wehrden, H. A novel bioenergy feedstock in Latin America? Cultivation potential of Acrocomia aculeata under current and future climate conditions. Biomass Bioenergy 2016, 91, 186-195. https://doi.org/10.1016/j.biombioe.2016.04.009

Poetsch, J.; Haupenthal, D.; Lewandowski, I.; Oberländer, D., Hilger, T. Acrocomia aculeata - a sustainable oil crop. Rural 2012, 21 (3), 41-44.

Roman, C. J. C. Análisis de um sub-sector de la industria de Productos no Maderables del Bosque (PNMB) del Paraguay. Kaàguy Revista Forestal del Paraguay 1996, 12 (1), 41-47.

Silva, R. J. N. B. Spreadsheet for designing valid leastsquares calibrations: A tutorial. Talanta. 2016, 148, 177190. https://doi.org/10.1016/j.talanta.2015.10.072

Singanan, M. Removal of lead (II) and cadmium (II) ions from wastewater using activated biocarbon. Science Asia 2011, 37, 115-119. https://doi.org/10.2306/scienceasia15131874.2011.37.115

Stefan, D. S.; Belcu, M.; Stefan, M.; Marinescu, I. A. Sorption of $\mathrm{Hg}^{2+}$ and $\mathrm{Pb}^{2+}$ ions from aqueous solutions on corn cobs biomaterials. Rev. Chim. 2010, 61 (1), 31-35.

Tchounwou, P. B.; Yedjou, C. G.; Patlolla, A. K.; Sutton, D. J. Heavy metal toxicity and the environment. In Molecular, Clinical and Environmental Toxicology; Luch, A., Ed.; Springer, 2012; pp 133-164. https://doi.org/10.1007/978-37643-8340-4_6

Tong, S.; von Schirnding, Y. E.; Prapamontol, T. Environmental lead exposure: a public health problem of global dimensions. Bull. World Health Organ. 2000, 78 (9), 1068-1077.
Wang, X.; Wang, L.; Wang, Y.; Tan, R.; Ke, X.; Zhou, X.; Geng, J.; Hou, H.; Zhou, M. Calcium sulfate hemihydrate whiskers obtained from flue gas desulfurization gypsum and used for the adsorption removal of lead. Crystals 2017, 7 (9), 270. https://doi.org/10.3390/cryst7090270

Yubero, F.; Ayala, J.; López, M.; Valdovinos, V.; Bernal, C.; González, Y. Polvo insoluble de pulpa de coco (Acrocomia aculeata) como biocatalizador. In $X X V$ Congreso Iberoamericano de Catálisis (CICat 2016), Montevideo, Uruguay, September 18-23, 2016a.

Yubero, F.; Ayala, J.; Lopez, M., Valdovinos, V.; Monteiro, M.; Gonzalez, Y.; Thompson, W.; Arguello, J. Physicochemical characteristics of the coconut pulp (Acrocomia aculeata) for use as support of proteins and metal material. In 22 Congreso Brasilero de Ingenieria y Ciencia de los Materiales (CBCIMAT 2016), Natal, Brazil, November 6-10, 2016b.

Yubero, F.; Oviedo, C.; Arango, M. Biomateriales de fuentes naturales para la retención de Cromo (VI). Rev. Soc. Cient. Parag. 2015, 20 (2), 135-143.

Zulkali, M. M. D.; Ahmad, A. L.; Norulakmal, N. H.; Sharifah, N. S. Comparative studies of Oryza sativa L. husk and chitosan as lead adsorbent. J. Chem. Technol. Biotechnol. 2006, $81 \quad$ (7), $1324-1327$. https://doi.org/10.1002/jctb.1429 